\title{
Tinjauan Kinerja Simpang Empat Bersinỵal Menggunakan Program KAJl dan SIDRA (Studi Kasus: Simpang Pasar Moodu, Gorontalo)
}

\author{
A.W. Arsyad ${ }^{a}$, Y. Kadir ${ }^{a *}$ dan F.L. Desei ${ }^{a}$ \\ a Jurusan Teknik Sipil, Fakultas Teknik Universitas Negeri Gorontalo, Gorontalo, Indonesia 96128 \\ *Corresponding author's e-mail: yuliyanti kadir@ung.ac.id
}

Received: 30 December 2021; revised: 15 January 2022; accepted: 22 January 2022

\begin{abstract}
The Moodu Market intersection is a signalized intersection formed by the convergence of Jalan Sultan Botutihe-Jalan Matolodula and Jalan Prof Dr. H. Aloei Saboe. This intersection is one of the accesses to the Aloei Saboe Hospital, Fourth Campus of the State University of Gorontalo, offices in Bone Bolango Regency, and close to Moodu market. Large traffic flows that pass through this intersection causes congestion. The purpose of this research was to analyze the permormance of the intersection to determine the level of service at the intersection. The analytical method used to determine the performance of the intersection was conducted using the KAJI and SIDRA programs. Observations were conducted in three days (Monday, 22 March 2021; Thursday, 25 March 2021; and Sunday, 28 March 2021) starting att 06.00-18.00 WITA. The data used in the analysis included the intersection's geometry, signal time, traffic volume, side barrier, cruise speed, pedestrian, and the population of Gorontalo City. The data was processed to find the values used to determine the performance of the intersection. Based on the results of analysis using the KAJI program, the average delay was 16.73 seconds for the north approach (Jalan Prof. Dr. H. Aloei Saboe), 12.75 seconds for the south approach (Jalan Matolodula), 25.86 seconds for the east approach (Jalan Sultan Botutihe), and 52.67 secinds for the west approach (Jalan Sultan Botutihe). Meanwhile, the results of the analysis using the SIDRA program showed that the average delay was 64.4 seconds for the north approach (Jalan Prof. Dr. H. Aloei Saboe), 13.1 seconds for the south approach (Jalan Matolodula), 42.0 seconds for the east approach (Jalan Sultan Botutihe), and 13.3 seconds the west approach (Jalan Sultan Botutihe). The average delay of the intersection based on the KAJI program was 32.11 seconds where its Level of Service was D while the average delay of the intersection based on the SIDRA program was 36.8 secinds whereas its Level of Service was D. The average percentage difference in the intersection delay using the KAJI and SIDRA Program was $12.75 \%$.
\end{abstract}

Keywords: signalized intersection, Moodu Market, KAJI, SIDRA

Abstrak: Simpang empat Pasar Moodu merupakan salah satu simpang bersinyal pertemuan antara ruas Jalan Sultan Botutihe-Jalan Matolodula dan Jalan Prof Dr. H. Aloei Saboe. Simpang ini adalah salah satu akses menuju RS. Aloei Saboe, Kampus empat Universitas Negeri Gorontalo, lokasi perkantoran di Kabupaten Bone Bolango serta dekat dengan pasar Moodu. Banyaknya arus lalu lintas yang melewati simpang ini menyebabkan kemacetan. Tujuan penelitian ini adalah menganalisis kinerja simpang untuk mengetahui tingkat pelayanan simpang. Metode analisis yang digunakan untuk menentukan kinerja simpang dilakukan dengan menggunakan program KAJI dan SIDRA. Pengamatan dilakukan selama tiga hari (Senin, 22 Maret 2021; Kamis, 25 Maret 2021; dan Minggu, 28 Maret 2021 ) mulai pukul 06.00-18.00 WITA. Data yang digunakan pada proses analisis merupakan data yang mencakup data geometrik simpang, waktu sinyal, volume lalu lintas, hambatan samping, kecepatan sesaat, pedestrian, dan data jumlah penduduk Kota Gorontalo. Setelah data dimasukkan, selanjutnya data diproses dan diolah untuk mencari nilai-nilai yang digunakan untuk menentukan kinerja simpang. Berdasarkan hasil analisis menggunakan program KAJI didapat nilai tundaan rata-rata pada pendekat utara (Jalan Prof. Dr. H. Aloei Saboe) sebesar 16,73 detik, pendekat selatan (Jalan Matolodula) sebesar 12,75 detik, pendekat timur (Jalan Sultan Botutihe) sebesar 25,86 detik, dan pendekat barat (Jalan Sultan Botutihe) sebesar 52,67 detik. Berdasarkan hasil analisis menggunakan program SIDRA didapat nilai tundaan rata-rata pada pendekat utara (Jalan Prof. Dr. H. Aloei Saboe) sebesar 64,4 detik, pendekat selatan (Jalan Matolodula) sebesar 13,1 detik, pendekat timur (Jalan Sultan Botutihe) sebesar 42,0 detik, dan pendekat barat (Jalan Matolodula) sebesar 13,3 detik. Nilai tundaan rata-rata simpang berdasarkan program KAJI sebesar 32,11 detik dengan tingkat pelayanan LOS D sedangkan nilai tundaan rata-rata simpang berdasarkan program SIDRA sebesar 36,8 detik dengan tingkat pelayanan LOS D. Rata-rata persentase berbedaan nilai tundaan simpang menggunakan program KAJI dan SIDRA sebesar $12,75 \%$.

Kata kunci: simpang bersinyal, Pasar Moodu, KAJI, SIDRA

\section{Pendahuluan}

Simpang merupakan daerah dimana dua atau lebih ruas jalan bergabung atau bersilangan termasuk jalan dan fasilitas tepi jalan untuk pergerakan lalu lintas pada area tersebut [1]. Sebuah persimpangan baik simpang bersinyal atau simpang tak bersinyal tidak luput dari suatu permasalahan lalu lintas seperti kemacetan, konflik pergerakan arus lalu lintas, panjang antrian pada kendaraan, derajat kejenuhan, dan kondisi fisik dari persimpangan tersebut [2].
Simpang empat Pasar Moodu merupakan simpang bersinyal pertemuan antara ruas Jalan Sultan Botutihe-Jalan Matolodula, dan Jalan Prof. Dr. H. Aloei Saboe. Simpang ini digunakan sebagai salah satu akses menuju RS. Aloei Saboe, Kampus empat Universitas Negeri Gorontalo, dan lokasi perkantoran di Kabupaten Bone Bolango. Simpang ini juga merupakan simpang yang berada dekat dengan lokasi pasar Moodu, pertokoan, dan usaha lainnya. Meski telah terpasang lampu lalu lintas, sering terjadi kemacetan pada simpang empat pasar Moodu terutama pada saat pasar 
beroperasi. Kemacetan yang terjadi dapat mempengaruhi kinerja simpang.

Penelitian ini menggunakan dua program untuk menentukan kinerja simpang yaitu program KAJI (Kapasitas Jalan Indonesia) dan SIDRA (Signalised and Unsignalised Intersection Design and Research Aid). Program KAJI merupakan program yang dasar perhitungan berpedoman pada MKJI 1997 [3]. Hasil analisis yang dilakukan oleh program KAJI dan SIDRA dapat memperkirakan nilai kapasitas, derajat kejenuhan, tundaan, dan tingkat pelayanan pada kondisi eksisting simpang.

Tujuan dari penelitian ini untuk menganalisis kinerja simpang empat bersinyal menggunakan program KAJI dan program SIDRA serta membandingkan hasil analisis kinerja simpang menggunakan kedua program tersebut.

Penelitian mengenai analisis kinerja simpang menggunakan program MKJI 1997 dan SIDRA serta perbandingan kinerja simpang menggunakan program SIDRA dan beberapa program lain pernah dilakukan pada tahun 2014 di simpang Pondok Kelapa, Medan [4], dan pada simpang Jalan 14 Februari-Jalan Tololiu Supit-Jalan Babe Palar, Kota Manado [5], serta pada tahun 2013 pada simpang Setia Budi-Dr. Mansyur dan Dr. Mansyur-Jamin Ginting [6]. Penelitian lain mengenai Kinerja simpang juga pernah dilakukan pada tahun 2020 pada simpang Jalan Ir. H. Juanda-Brigjen Katamso, Medan [7] dan pada tahun 2019 pada simpang Mitra Batik Kota Tasikmalaya [2].

Penelitian yang pernah dilakukan diluar Indonesia antara lain tentang Comparative Study of Vissim and SIDRA on Signalized Intersiction pada tahun 2013 [8] dan pada tahun 2014 tentang Evaluating Operational Performance of Intersections Using SIDRA [9].

\section{Metode Penelitian}

\subsection{Lokasi Penelitian}

Penelitian ini dilakukan di Kecamatan Kota Timur, Kota Gorontalo pada simpang lengan empat bersinyal yaitu simpang empat pasar Moodu, Jalan Prof. Dr. H. Aloei Saboe-Jalan Sultan Botutihe, dan Jalan Matolodula (Gambar 1).

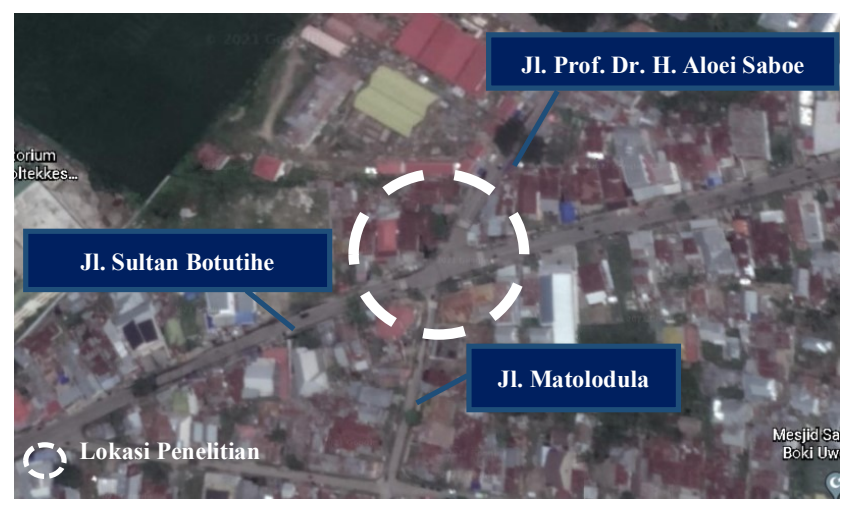

Gambar 1. Peta lokasi penelitian

\subsection{Data}

Data yang digunakan dalam penelitian ini adalah data primer dan data sekunder. Data primer merupakan data yang diperoleh melalui survei langsung pada lokasi penelitian. Data primer mencakup data geometrik simpang, waktu sinyal, volume lalu lintas, hambatan samping, kecepatan sesaat, dan pedestrian. Data sekunder merupakan data yang diperoleh dari Badan Pusat Statistik Provinsi Gorontalo yang berupa data jumlah penduduk di Kota Gorontalo.

\subsection{Metode dan Tahapan Penelitian}

\subsubsection{Metode Analisis Data Menggunakan Program KAJI}

Sistem operasi KAJI terdiri dari tahap input data, proses dan hasil output. Program KAJI memiliki lima formulir yang harus diisi untuk menentukan nilai kinerja pada simpang yang akan diteliti. Lima formulir pada program KAJI terdiri atas SIG 1-SIG 5 dimana terdapat data yang diinput pada masing-masing formulir berbeda-beda. Setelah data selesai diinput, kemudian diproses untuk menghasilkan nilai kapasitas, derajat kejenuhan, panjang antrian, dan lainnya. Berikut ini adalah tampilan program KAJI (Gambar 2).

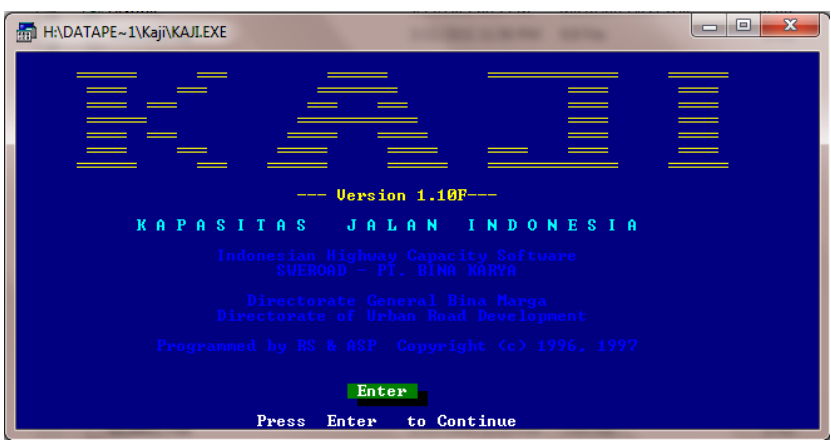

Gambar 1. Tampilan Program KAJI

2.3.2. Metode Analisis Data Menggunakan Program SIDRA

Sistem operasi SIDRA terbagi dalam tiga bagian yaitu tahap input data, tahap perhitungan, dan tahap output data. SIDRA menggunkan model analisis lalu lintas secara detail dan digabungkan dengan metode perkiraan untuk memberikan perkiraan kapasitas dan tampilan statistik dari keterlambatan, antrian, perhentian, dan lain lain [10-11]. Berikut ini adalah tampilan program SIDRA (Gambar 3).

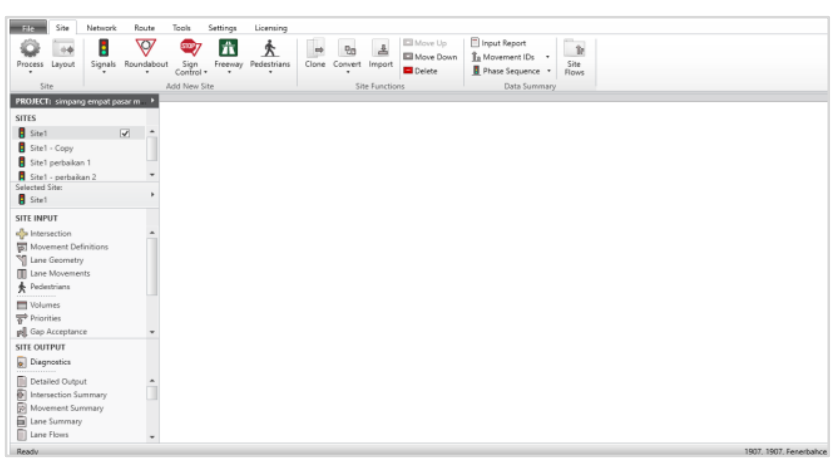

Gambar 2. Tampilan Program SIDRA

\subsubsection{Tahap Pengumpulan Data}

\section{1). Data Primer}

Data primer merupakan data yang didapatkan dari hasil survei langsung pada lokasi penelitian. Data primer yang diambil meliputi:

a) Geometrik simpang 
Survei geometrik simpang dilakukan untuk mengetahui keadaan di persimpangan. Data geometrik diperoleh dari hasil pengukuran menggunakan meteran. Data yang diukur meliputi lebar lajur lalu lintas, lebar bahu jalan, dan lebar median (jika ada).

b) Data volume arus lalu lintas

Volume arus lalu lintas diambil melalui survei pada jam-jam sibuk di setiap lengan persimpangan. Data volume lalu lintas dihitung menggunakan tally counter. Data volume arus lalu lintas diambil dalam periode tiap 15 menit selama 12 jam. Waktu pelaksanaan survei dilakukan pada pagi hari pukul 06:00 WITA hingga 18:00 WITA. Jenis kendaraan yang akan disurvei terdiri atas kendaraan ringan, kendaraan berat, sepeda motor, dan kendaraan tak bermotor.

c) Waktu sinyal

Survei waktu sinyal dilakukan untuk mengetahui pengaturan tiap-tiap waktu pada masing-masing lengan simpang [12-13]. Survei ini dilakukan dengan menggunakan stopwatch. Data yang diambil adalah waktu siklus yang terdiri dari waktu lampu hijau, merah, dan kuning.

d) Hambatan samping

Data hambatan samping diambil pada jarak $200 \mathrm{~m}$ dari simpang pada setiap pendekat. Jenis hambatan samping yang dihitung terdiri atas pejalan kaki, kendaraan berhenti, kendaraan yang masuk/keluar sisi jalan, dan kendaraan melambat. Hambatan samping dihitung dalam periode tiap 15 menit.

\section{e) Kecepatan sesaat}

Kecepatan sesaat digunakan sebagai acuan dalam penentuan kecepatan untuk keadaan keluar atau masuk dari setiap pendekat. Penentuan kecepatan sudah dikatakan sesuai dengan keadaan eksisting. Kecepatan sesaat disurvei dengan jarak 100 meter dari mulut simpang.

\section{f) Pedestrian (Pejalan Kaki)}

Pedestrian merupakan jumlah orang yang menyebrang melalui tempat penyebrangan (zebra cross). Data pedestrian disurvei tiap 15 menit selama 12 jam pada setiap pendekat.

\section{2). Data Sekunder}

Data sekunder yang diperlukan dalam penelitian ini berupa data jumlah penduduk Kota Gorontalo menurut Badan Pusat Statistik Provinsi Gorontalo Tahun 2021 [14].

\section{Hasil dan Pembahasan}

\subsection{Gambaran Umum Lokasi Penelitian}

Penelitian ini mengambil lokasi pada simpang empat pasar Moodu yang terletak di Kelurahan Moodu, Kecamatan Kota Timur, Kota Gorontalo dengan jumlah penduduk sebanyak 198.539 jiwa menurut Badan Pusat Statistik Provinsi Gorontalo Tahun 2021 [14].

\subsection{Geometrik Simpang}

Simpang sempat pasar Moodu merupakan simpang empat lengan yang terdiri dari jalan Jalan Prof. Dr. H. Aloei Saboe (arah utara), Jalan Matolodula (arah selatan), dan Jalan Sultan Botutihe (arah timur dan barat). Geometrik pada simpang empat pasar Moodu ditunjukkan pada Gambar 4.

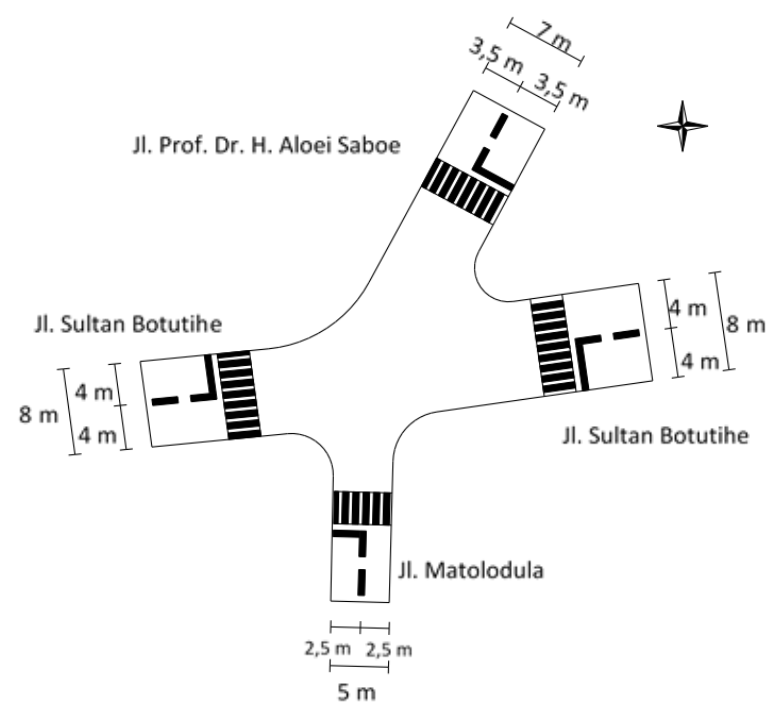

Gambar 3. Kondisi geometrik simpang empat Pasar Moodu

Survei geometrik simpang dilakukan pada saat kondisi jalan sepi dari kendaraan untuk menghindari gangguan arus lalu lintas. Data geometrik simpang empat pasar Moodu ditunjukkan pada Tabel 1.

Tabel 1. Data geometrik simpang

\begin{tabular}{lllll}
\hline \multicolumn{1}{c}{ Pendekat } & Utara & Selatan & Timur & Barat \\
\hline Tipe Lingkungan Jalan & $C O M$ & $R E S$ & $C O M$ & $C O M$ \\
\hline Median & $\begin{array}{l}\text { tidak } \\
\text { ada }\end{array}$ & $\begin{array}{l}\text { tidak } \\
\text { ada }\end{array}$ & $\begin{array}{l}\text { tidak } \\
\text { ada }\end{array}$ & $\begin{array}{l}\text { tidak } \\
\text { ada }\end{array}$ \\
\hline Belok Kiri Jalan Terus & Tidak & Tidak & Tidak & Tidak \\
\hline lebar jalan (m) & 7 & 5 & 8 & 8 \\
\hline $\begin{array}{l}\text { lebar pendekat masuk } \\
(\mathrm{m})\end{array}$ & 3,5 & 2,5 & 4 & 4 \\
\hline $\begin{array}{l}\text { lebar pendekat keluar } \\
(\mathrm{m})\end{array}$ & 3,5 & 2,5 & 4 & 4 \\
\hline
\end{tabular}

\subsection{Volume Lalu Lintas}

Pengambilan data volume lalu lintas dilakukan pada setiap lengan persimpangan. Data volume lalu lintas dicatat setiap 15 menit selama 12 jam dimulai pada pukul 06:00 WITA hingga 18:00 WITA selama tiga hari yaitu pada hari Senin (22 Maret 2021), Kamis (25 Maret 2021), dan Minggu (28 Maret 2021). Rekapitulasi volume kendaraan selama tiga hari ditunjukkan pada Gambar 5.

Volume jam puncak merupakan volume lalu lintas terbesar yang terjadi selama satu jam pengamatan. Berdasarkan hasil pengamatan selama hari Senin, Kamis, dan Minggu, didapatkan volume kendaraan terbesar pada hari Kamis dengan jam puncak pada pukul 16.30-17.30 
WITA. Volume kendaraan pada jam puncak untuk setiap jenis kendaraan ditunjukkan pada Tabel 2.

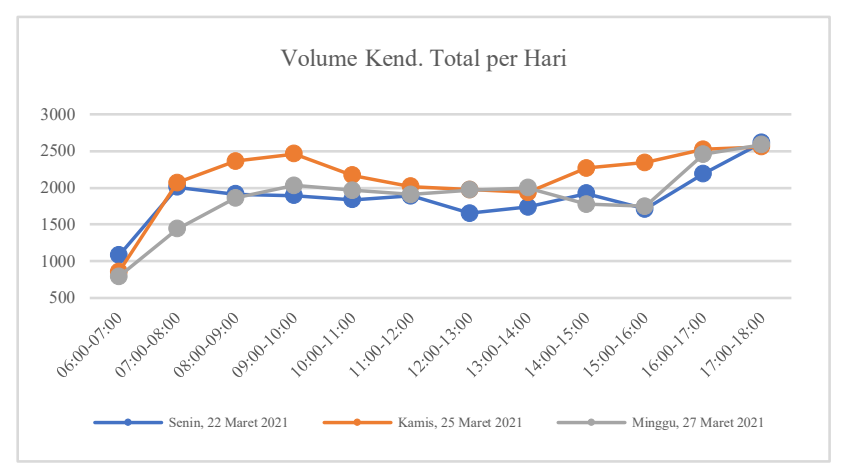

Gambar 4. Rekapitulasi Volume Lalu Lintas

Tabel 2. Volume Lalu Lintas Jam Puncak

\begin{tabular}{|c|c|c|c|c|c|}
\hline \multirow{2}{*}{ Pendekat } & \multirow{2}{*}{ Arah } & \multicolumn{3}{|c|}{ Jenis kendaraan } & \multirow{2}{*}{$\begin{array}{c}\text { Total } \\
\text { (smp/jam) }\end{array}$} \\
\hline & & $L V$ & $H V$ & $M C$ & \\
\hline \multirow[t]{4}{*}{ Utara } & $S T$ & 6 & 0 & 34.4 & 40.4 \\
\hline & $R T$ & 69 & 3.9 & 134.4 & 207.3 \\
\hline & $L T$ & 36 & 7.8 & 50 & 93.8 \\
\hline & LTOR & 31 & 0 & 56.4 & 87.4 \\
\hline \multirow[t]{4}{*}{ Selatan } & $S T$ & 9 & 0 & 46 & 55 \\
\hline & $R T$ & 1 & 0 & 8.4 & 9.4 \\
\hline & $L T$ & 2 & 0 & 1.6 & 3.6 \\
\hline & LTOR & 0 & 0 & 4.4 & 4.4 \\
\hline \multirow[t]{4}{*}{ Barat } & $S T$ & 120 & 3.9 & 164.4 & 288.3 \\
\hline & $R T$ & 49 & 2.6 & 49.2 & 100.8 \\
\hline & $L T$ & 5 & 0 & 6.4 & 11.4 \\
\hline & LTOR & 0 & 0 & 2 & 2 \\
\hline \multirow[t]{4}{*}{ Timur } & $S T$ & 120 & 6.5 & 172 & 298.5 \\
\hline & $R T$ & 2 & 0 & 1.6 & 3.6 \\
\hline & $L T$ & 73 & 2.6 & 62 & 137.6 \\
\hline & LTOR & 46 & 1.3 & 46.4 & 93.7 \\
\hline TOTAL & & & & & 1437.2 \\
\hline
\end{tabular}

\subsection{Hambatan Samping}

Survei hambatan samping dilakukan sepanjang $200 \mathrm{~m}$ setiap 15 menit selama 12 jam. Frekuensi kejadian hambatan samping diambil sesuai dengan waktu jam puncak volume lalu lintas yaitu pada hari kamis jam 16.3017.30 WITA. Nilai hambatan samping pada setiap pendekat ditunjukkan pada Tabel 3.

Tabel 3. Nilai hambatan samping

\begin{tabular}{lcccc}
\hline Pendekat & Utara & Selatan & Timur & Barat \\
\hline Pejalan Kaki & 35.5 & 16.5 & 7 & 9 \\
\hline Kend. Parkir & 82 & 26 & 63 & 21 \\
\hline $\begin{array}{l}\text { Kend. } \\
\text { Masuk/Keluar }\end{array}$ & 51.8 & 16.1 & 84 & 141,4 \\
\hline Kend. Lambat & 0.8 & 0.4 & 2.4 & 3.2 \\
\hline \multicolumn{1}{c}{ TOTAL } & 170.1 & 59 & 156.4 & 174,6 \\
\hline
\end{tabular}

Berdasarkan Tabel 3, hambatan samping simpang berada pada kategori rendah.

\subsection{Waktu Sinyal}

Berdasarkan hasil survei di lapangan simpang empat pasar Moodu menggunakan dua fase yaitu fase satu pada pendekat utara-selatan dan fase dua pada pendekat timurbara dengan waktu siklus total 50 detik. daktu sinyal simpang empat pasar moodu ditunjukkan pada Gambar 6 .

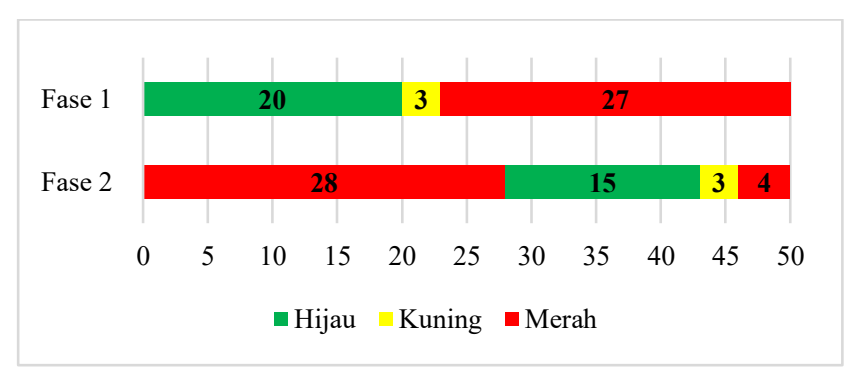

Gambar 5. Diagram waktu sinyal simpang empat Pasar Moodu

\subsection{Kecepatan Sesaat}

Kecepatan sesaat merupakan kecepatan pada saat kendaraan masuk dan keluar dari simpang. Nilai kecepatan sesaat yang digunakan dalam analisis diambil berdasarkan waktu jam puncak. Nilai rata-rata kecepatan sesaat kendaraan masuk simpang untuk pendekat utara 27,29 $\mathrm{km} / \mathrm{jam}$, selatan 20,26 km/jam, timur $21,12 \mathrm{~km} / \mathrm{jam}$, dan barat $20,38 \mathrm{~km} / \mathrm{jam}$. Nilai kecepatan sesaat kendaraan keluar simpang untuk pendekat utara $18,70 \mathrm{~km} / \mathrm{jam}$, selatan $20,21 \mathrm{~km} / \mathrm{jam}$, timur $20,41 \mathrm{~km} / \mathrm{jam}$, dan barat 19,04 $\mathrm{km} / \mathrm{jam}$.

\subsection{Pedestrian}

Data pedestrian didapatkan dari survei langsung di lapangan dengan menghitung jumlah orang yang menyebrang melalui tempat penyebrangan (zebra cross) pada jam puncak. Data pedestrian pada jam puncak ditunjukkan pada Tabel 4.

Tabel 4. Jumlah Pedestrian pada Jam Puncak

\begin{tabular}{cc}
\hline Pendekat & Jumlah Pejalan Kaki \\
\hline Utara & 1 \\
\hline Selatan & 2 \\
\hline Timur & 1 \\
\hline Barat & 10 \\
\hline
\end{tabular}

Berdasarakan Tabel 4, jumlah pedestrian yang melewati simpang sebanyak 14 orang.

\subsection{Analisis Kinerja Simpang Menggunakan Program KAJI}

\subsubsection{Derajat Kejenuhan (DS)}

Nilai DS diperoleh dari hasil perbandingan arus lalu lintas dengan kapasitas simpang. kapasitas simpang. Arus lalu lintas merupakan jumlah volume lalu lintas saat jam puncak pada setiap pendekat yang telah dikonversi menjadi satuan mobil penumpang dengan tipe arus lalu lintas terlawan (opposed). Nilai derajat kejenuhan ditunjukkan pada Tabel 5. 
REKOnSTRUKSI TADULAKO: Civil Engineering Journal on Research and Development, Vol. 3(1), March 2022

Tabel 5. Nilai derajat kejenuhan menggunakan Program KAJI

\begin{tabular}{cccc}
\hline Pendekat & $\begin{array}{c}\mathbf{Q} \\
\text { (smp/jam) }\end{array}$ & $\begin{array}{c}\text { C } \\
\text { (smp/jam) }\end{array}$ & DS \\
\hline Utara & 341 & 612 & 0,557 \\
\hline Selatan & 68 & 302 & 0,225 \\
\hline Timur & 400 & 539 & 0,742 \\
\hline Barat & 441 & 480 & 0,919 \\
\hline
\end{tabular}

Berdasarkan Tabel 5, nilai derajat kejenuhan simpang adalah 0,611 .

\subsubsection{Panjang Antrian (QL)}

QL merupakan panjang kendaraan yang antri dalam suatu pendekat. Nilai panjang antrian pada setiap pendekat ditunjukkan pada Tabel 6 .

Tabel 6. Panjang antrian menggunakan Program KAJI

\begin{tabular}{cc}
\hline Pendekat & Panjang Antrian $(\boldsymbol{Q} \boldsymbol{l})$ \\
\hline Utara & 29,00 \\
\hline Selatan & 8,00 \\
\hline Timur & 40,00 \\
\hline Barat & 70,00 \\
\hline
\end{tabular}

Berdasarkan Tabel 6, nilai QL pada setiap pendekat berbeda-beda. Nilai QL terbesar berada pada pendekat barat sebesar $70 \mathrm{~m}$ dan QL terkecil berada pada pendekat selatan sebesar $8 \mathrm{~m}$

\subsubsection{Tundaan (D)}

Tundaan merupakan tambahan waktu tempuh tambahan yang diperlukan untuk melewati suatu simpang. Menurut MKJI 1997, D terdiri dari Tundaan Lalu Lintas (DT) dan Tundaan Geometrik (DG). Nilai tundaan pada setiap pendekat ditunjukkan pada Tabel 7.

Tabel 7. Nilai tundaan meggunakan Program KAJI

\begin{tabular}{ccccc}
\hline Pendekat & $\begin{array}{c}\text { Tundaan } \\
\text { Lalu } \\
\text { Lintas } \\
\text { Rata-rata } \\
(\boldsymbol{D} \boldsymbol{T})\end{array}$ & $\begin{array}{c}\text { Tundaan } \\
\text { Geometrik } \\
\text { Rata-rata } \\
(\boldsymbol{D} \boldsymbol{G})\end{array}$ & $\begin{array}{c}\text { Tundaan } \\
\text { Rata-rata } \\
(\boldsymbol{D}=\boldsymbol{D} \boldsymbol{T}+\boldsymbol{D} \boldsymbol{G})\end{array}$ & $\begin{array}{c}\text { Tundaan } \\
\text { Total } \\
(\boldsymbol{D} \times \boldsymbol{Q})\end{array}$ \\
\hline Utara & 12,34 & 4,39 & 16,73 & 5.706 \\
\hline Selatan & 9,89 & 2,86 & 12,75 & 867 \\
\hline Timur & 21,95 & 3,91 & 25,86 & 10.343 \\
\hline Barat & 48,67 & 4,00 & 52,67 & 23.227 \\
\hline
\end{tabular}

Tabel 7 menunjukkan nilai tundaan terbesar terdapat pada pendekat barat sebesar 52,67 detik dan nilai tundaan terkecil berada pada pendekat selatan sebesar 12,75 detik.

\subsubsection{Tingkat Pelayanan (LOS)}

Tingkat pelayanan merupakan suatu parameter yang digunakan untuk menilai kinerja jalan yang menjadi indikator kemacetan Tingkat pelayanan simpang yang digunakan di Indonesia mengacu pada Peraturan Menteri Perhubungan Republik Indonesia No. 96 Tahun 2015 [15].

Berdasarkan Peraturan Menteri No. 96 Tahun 2015, tingkat pelayanan simpang ditentukan dari besarnya tundaan yang terjadi pada setiap pendekat. Tingkat pelayanan simpang berdasarkan analisis KAJI ditunjukkan pada Tabel 8.

Tabel 8. Tingkat Pelayanan Berdasarkan Analisis KAJI

\begin{tabular}{ccc}
\hline Pendekat & Waktu Tundaan & LOS \\
\hline Utara & 16,73 & $\mathrm{C}$ \\
\hline Selatan & 12,75 & $\mathrm{~B}$ \\
\hline Timur & 25,86 & $\mathrm{D}$ \\
\hline Barat & 52,67 & $\mathrm{E}$ \\
\hline
\end{tabular}

Tabel 8 menunjukkan nilai tundaan rata-rata untuk simpang empat pasar Moodu sebesar 32,11 detik. Hal ini menunjukkan bahwa simpang empat pasar Moodu memiliki tingkat pelayanan LOS D.

\subsection{Analisis Kinerja Simpang Menggunakan Program SIDRA}

\subsubsection{Fase Sinyal}

Fase sinyal yang digunakan dalam analisa kinerja simpang merupakan fase sinyal yang dianalisis menggunakan program SIDRA dengan waktu siklus 50 detik. Fase A merupakan fase pada pendekan utara dan selatan sedangkat fase B merupakan fase pada pendekat timur dan barat. Fase sinyal simpang berdasarkan program SIDRA ditunjukkan pada Gambar 7.



Gambar 6. Fase Sinyal Simpang Berdasarkan Program SIDRA

Berdaasrkan Gambar 7, waktu hijau pada fase A adalah 16 detik dan fase B adalah 19 detik. Waktu hijau yang digunakan untuk analisis kinerja simpang pada program SIDRA ini berbeda dengan waktu hijau di lapangan dimana waktu hijau pada fase A dan B masing-masing sebesar 20 dan 15 detik.

\subsubsection{Kapasitas (C) dan Derajat Kejenuhan (DS)}

Kapasitas dan derajat kejenuhan pada program SIDRA diperoleh dari hasil simulasi pergerakan lalu lintas yang terjadi dari masing-masing pendekat simpang. Nilai kapasitas yang diperoleh dari hasil analisis menggunakan program SIDRA ditunjukkan dalam Tabel 9.

Tabel 9. Nilai kapasitas dan derajat kejenuhan menggunakan Program SIDRA

\begin{tabular}{ccccc}
\hline \multirow{2}{*}{ Pendekat } & \multicolumn{2}{c}{ Arus Kendaraan } & & \\
\cline { 2 - 3 } & $\begin{array}{c}\text { Total } \\
\text { Volume } \\
\text { Kendaraan } \\
\text { (kend/jam) }\end{array}$ & $\begin{array}{c}\text { Persentase } \\
\boldsymbol{H} \boldsymbol{V}(\%)\end{array}$ & $\begin{array}{c}\text { C } \\
\text { (kend/jam) }\end{array}$ & DS \\
\hline Utara & 702 & 1,3 & 669 & 0,14 \\
\hline Selatan & 160 & 0 & 1.158 & 0,98 \\
\hline Timur & 767 & 0,7 & 781 & 1,05 \\
\hline Barat & 833 & 0,9 & 1.538 & 0,54 \\
\hline
\end{tabular}

Berdasarkan Tabel 9, nilai total volume kendaraan pada simpang empat pasar Moodu sebssar $2.462 \mathrm{kend} / \mathrm{jam}$. Persentase HV merupakan persentase banyaknya jumlah kendaraan berada dalam total volume kendaraan pada setiap pendekat. Nilai DS untuk simpang empat pasar Moodu 
mencapai 1,05. Nilai DS untuk simpang ini diambil berdasarkan nilai derajat kejenuhan tertinggi dari keempat pendakat.

\subsubsection{Panjang Antrian (QL), Tundaan (D), dan Tingkat Pelayanan (LOS)}

Panjang antrian merupakan panjang kendaraan yang antri dalam suatu lengan atau pendekat simpang. Nilai tundaan merupakan faktor utama dalam menentukan tingkat pelayanan dalam anlisis menggunakan program SIDRA. Nilai Panjang Antrian, Tundaan dan Tingkat Pelayanan simpang dapat dilihat pada Tabel 10 .

Tabel 10. Tingkat Pelayanan Berdasarkan Analisis SIDRA

\begin{tabular}{cccc}
\hline Pendekat & $\begin{array}{c}\text { Panjang } \\
\text { Antrian }(\mathbf{m})\end{array}$ & Tundaan & LOS \\
\hline Utara & 72 & 64,6 & $\mathrm{~F}$ \\
\hline Selatan & 5 & 13,1 & $\mathrm{~B}$ \\
\hline Timur & 67 & 42,0 & $\mathrm{E}$ \\
\hline Barat & 37 & 13,3 & $\mathrm{~B}$ \\
\hline
\end{tabular}

3.10. Perbandingan Kinerja Simpang Menggunakan Program KAJI dan SIDRA

Hasil analisis kinerja simpang menggunakan program KAJI dan SIDRA menunjukkan perbedaan yang signifikan pada beberapa parameter yang disebabkan oleh proses anailis yang berbeda pada kedua program (Tabel 11). Kapasitas simpang merupakan salah satu dari parameter simpang yang mengalami perubahan signifikan setelah dianalisis menggunakan program KAJI dan SIDRA. Satuan Kapasitas yang digunakan pada program KAJI adalah smp/jam dan program SIDRA adalah kend/jam. Hal ini dikarenakan hasil konversi arus lalu lintas pada program KAJI memiliki satuan smp/jam sedangkan pada program SIDRA tetap menggunakan satuan kend/jam setelah dikonversi.

Tabel 11. Perbandingan kinerja simpang

\begin{tabular}{ccccccc}
\hline Pendekat & Program & C & DS & QL & D & LOS \\
\hline \multirow{2}{*}{ Utara } & KAJI & 612 & 0,557 & 29 & 16,73 & $\mathrm{C}$ \\
\cline { 2 - 7 } & SIDRA & 669 & 1,05 & 72 & 64,4 & $\mathrm{~F}$ \\
\hline \multirow{2}{*}{ Selatan } & KAJI & 302 & 0,225 & 8 & 12,75 & $\mathrm{~B}$ \\
\cline { 2 - 7 } & SIDRA & 1.158 & 0,14 & 5 & 13,1 & $\mathrm{~B}$ \\
\hline \multirow{2}{*}{ Timur } & KAJI & 539 & 0,742 & 40 & 25,86 & $\mathrm{D}$ \\
\cline { 2 - 7 } & SIDRA & 781 & 0,98 & 67 & 42,00 & $\mathrm{E}$ \\
\hline Barat & KAJI & 480 & 0,919 & 70 & 52,67 & $\mathrm{E}$ \\
\cline { 2 - 6 } & SIDRA & 1.538 & 0,54 & 37 & 13,3 & $\mathrm{~B}$ \\
\hline
\end{tabular}

Perbedaan hasil analisis ini disebabkan oleh adanya beberapa faktor seperti:

1). Perbedaan data masukan pada lebar jalan dimana pada program KAJI data yang di input merupakan data per jalur sedangkan pada program SIDRA merupakan data per lajur,

2). Nilai konversi yang digunakan untuk mengorversikan arus lalu lintas menggunakan program KAJI dan SIDRA berbeda

3). Program KAJI memerlukan data jumlah penduduk dalam proses analisis sedangkan pada program SIDRA tidak,
4). Data input Waktu siklus pada program KAJI terdiri atas waktu hijau dan waktu antar hijau (waktu kuning dan all red) sedangkan pada program SIDRA hanya merupakan waktu siklus total, waktu kuning, dan waktu all red pada setiap fase sehingga waktu hijau yang diambil merupakan data hijau yang dianalisis pada program SIDRA dan berbeda pada waktu hijau di lapangan,

5). Program KAJI memerlukan data hambatan samping dengan memperhatinkan tipe lingkungan jalan sedangkan pada program SIDRA tidak,

6). Data pejalan kaki merupakan data yang diperlukan dalam analisis pada program SIDRA sedangkan pada program KAJI tidak,

7). Kecepatan kendaraan pada saat masuk dan keluar simpang juga diperlukan dalam analisis program SIDRA sedangkan pada program KAJI tidak diperlukan.

\section{Kesimpulan}

Berdasarkan analisis kinerja terhadap simpang empat pasar Moodu diperoleh beberapa kesimpulan sebagai berikut:

1). Hasil analisis kinerja simpang menggunakan program KAJI menunjukkan nilai derajat kejenuhan untuk pendekat utara 0,557 ; pendekat selatan 0,225 ; pendekat timur 0,742; dan pendekat barat 0,919 dan nilai tundaan rata-rata pada pendekat utara sebesar 16,73 det/smp; pendekat selatan $12,75 \mathrm{det} / \mathrm{smp}$; pendekat timur 25,86 $\mathrm{det} / \mathrm{smp}$; dan pendekat barat 52,67 det/smp. Tundaan rata-rata simpang sebesar $32,11 \mathrm{det} / \mathrm{smp}$. Tingkat pelayanan simpang empat pasar Moodu adalah D. Tingkat pelayanan untuk setiap pendekat adalah sebagai berikut: pendekat utara LOS C; pendekat selatan LOS B; pendekat timur LOS D; dan pendekat barat LOS E.

2). Hasil analisis kinerja simpang menggunakan program SIDRA menunjukkan nilai derajat kejenuhan pada pendekat utara 1,05; pendekat selatan 0,14 ; pendekat timur 0,98; dan pendekat barat 0,54 dan nilai Tundaan rata-rata pada pendekat utara sebesar 64,4 det/smp; pendekat selatan 13,1 det/smp; pendekat timur 42,0 $\mathrm{det} / \mathrm{smp}$; dan pendekat barat 13,3 det/smp. Tundaan ratarata simpang sebesar $36,8 \mathrm{det} / \mathrm{smp}$. Tingkat pelayanan simpang empat pasar Moodu adalah D. Tingkat pelayanan untuk setiap pendekat adalah sebagai berikut: pendekat utara LOS F; pendekat selatan LOS B; pendekat timur LOS E; dan pendekat barat LOS B.

3). Perbandingan hasil analisis kinerja simpang menunjukkan nilai derajat kejenuhan pada pendekat utara dan timur lebih besar pada analisis menggunakan program SIDRA dengan selisih sebesar 38,09\% sedangkan derajat kejenuhan pada pendekat selatan dan barat lebih besar menggunakan analisis program KAJI dengan selisih sebesar $45,45 \%$. Hasil analisis tundaan menggunakan program SIDRA pada pendekat utara, selatan, dan timur lebih besar dibandingkan hasil analisis pada program KAJI. Rata-rata persentase berbedaan nilai tundaan simpang sebesar $12,75 \%$. 


\section{Daftar Pustaka}

[1] AASHTO, A Policy on Geometric Design of Highways and Streets, Washington D.C.: AASHTO, 2001.

[2] R.W. Adri, N. Herlina, and A.K. Hidayat, "Analisis Kinerja Simpang Bersinyal (Studi Kasus Simpang Mitra Batik Kota Tasikmalaya)," Akselerasi, vol. 3, no. 1, p. 1, 2019.

[3] Direktorat Jenderal Bina Marga, Manual Kapasitas Jalan Indonesia (MKJ), Jakarta: Departemen Pekerjaan Umum, 1997.

[4] J.B. Siahaan, Analisa Kinerja Simpang Lengan Empat Bersinyal dengan Menggunakan Program KAJI dan SIDRA (Studi Kasus: Simpang Pondok Kelapa, Medan)," Medan: Universitas Sumatera Utara, 2014.

[5] P.I. Badar, T.K. Sendow, F.Jansen, and M. Manopo, "Analisa Persimpangan Tidak Bersinyal Menggunakan Program SIDRA (Studi Kasus Persimpangan Jalan 14 Februari-Jalan Tololiu SupitJalan Babe Palar, Kota Manado)," Jurnal Sipil Statik, vol. 2, no. 7, p. 367, 2014.

[6] M. Agung, Perbandingan Kinerja Simpang Bersinyal Berdasarkan Program KAJI dan SIDRA (Studi Kasus Simpang Setia Budi-Dr. Mansyur dan Dr. MansyurJamin Ginting)," Medan: Universitas Sumatera Utara, 2013.

[7] T.R.P. Nasution, "Evaluasi Kinerja Simpang Bersinyal dengan Menggunakan Program SIDRA dan MKJI 1997 (Studi Kasus: Persimpangan Jalan Ir. H. Juanda-Brigjen Katamso, Medan)," Medan: Universitas Sumatera Utara, 2020.

[8] T. Chen, S. Jin, and H. Yang, "Comparative Study of VISSIM and SIDRA on Signalized Intersection", Procedia - Social and Behavioral Sciences vol. 96, no. 6, p. 2004-2010, 2013.
[9] P. Ranjitkar, A. Shahin, and F. Shirwali, "Evaluating Operational Performance of Intersection Using SIDRA," The Open Transportation Journal, vol. 8, p. 50, 2014.

[10] A. Rahman, "Perencanaan Simpang Empat Bersinyal Pasar Lemabang Kota Palembang dengan Program Simulasi VISSIM", Cantilever: Jurnal Penelitian dan Kajian Bidang Teknik Sipil, vol 5, no 2, p. 7, 2016.

[11] H. Betaubun, A. Agustan, and A. Leploy, "Analisis Kinerja Simpang Empat Tak Bersinyal Menggunakan Aplikasi Kaji (Studi Kasus : Simpang Seringgu di Kabupaten Merauke)", MUSTEK, vol. 7, no. 3, p. 266, 2018.

[12] A. Safri, A.M.Das, and W. Dony, "Evaluasi Simpang Empat Bersinyal Jalan Kolonel Polisi M. Taher Kota Jambi”, Jurnal Talenta Sipil, vol. 4, no. 2, p. 94, 2021.

[13] S. Widyawan and Rukman, "Analisis Kinerja Simpang Bersinyal untuk Meningkatkan Keselamatan pada Simpang Depok Kota Depok", Airman: Jurnal Teknik dan Keselamatan Transportasi, vol. 2, no. 1, p. 30, 2019.

[14] Badan Pusat Statistik Provinsi Gorontalo, Provinsi Gorontalo Dalam Angka, Gorontalo: BPS Provinsi Gorontalo, 2021.

[15] Kementrian Perhubungan, Peraturan Menteri Perhubungan Republik Indonesia Nomor PM 96 Tahun 2015 Tentang Pedomen Pelaksanaan Manajemen dan Rekayasa Lalu Lintas, Jakarta: Menteri Perhubungan Republik Indonesia, 2015. 
